\title{
Posse de cativos e a hipótese do ciclo de vida - Guarapuava - Século xix
}

\section{Slave ownership and the life cicle hypothesis - Guarapuava - 19th Century}

\author{
Fernando Franco Netto*
}

\begin{abstract}
Resumo
Este trabalho procura abordar algumas questões sobre a estrutura de posse de escravos e o comportamento de alguns proprietários com relação ao seu ciclo de vida e a posse de cativos na região dos Campos Gerais do Paraná, mais especificamente em Guarapuava no século XIX, a partir dos registros referentes às listas nominativas de habitantes dos anos de 1828, 1835, $1840 \mathrm{e}$ dos inventários post-mortem. A política de ocupação da localidade promovida pelo Governo estava voltada para dois aspectos fundamentais: a defesa territorial e a expansão da fronteira. 0 tamanho dos plantéis demonstra um padrão de posse de pequenos plantéis, característica das economias voltadas para o abastecimento interno e com suas atividades relacionadas com o campo. A posse média de escravos se mostrou crescente nos períodos analisados. Isso reflete na importância do ciclo de vida e da formação do patrimônio de cada proprietário. A relação entre a posse de escravos e a faixa etária dos proprietários confirma a hipótese de que seu patrimônio cresce de acordo com a idade destes, com tendência de queda quando no final da vida.
\end{abstract}

Palavras-chave: Escravidão. Propriedade. Ciclo de vida. Fronteira.

\begin{abstract}
This paper seeks to address some issues about the structure of ownership of slaves and the behavior of some owners regarding its life cycle and ownership of slaves in the region of Campos Gerais, Paraná, more specifically in Guarapuava in the Nineteenth Century, from records relating to lists of registered inhabitants of the years 1828, 1835, 1840 and the post-mortem inventories. The policy of occupation of the town promoted by the Government was focused on two fundamental aspects: territorial defense as well as the expansion of the border. The size of goods demonstrates a pattern
\end{abstract}

\footnotetext{
* Doutor em História. Professor da Universidade Estadual do Centro-Oeste. E-mail: ffranconetto@yahoo. com.br
} 
Fernando Franco Netto

of ownership of few slaves, characteristic of economies facing domestic supplies and activities related to the field. The average possession of slaves was proven as increasing during the periods under focus. This reflects the importance of the life cycle and the formation of the equity of each slave owner. The relationship between the possession of slaves and the age of the owners confirms the hypothesis that one's equity grew according to age, with a declining trend on the of one's life.

Keywords: Slavery. Property. Life cycle. Border.

\section{Introdução}

Este trabalho procura, a partir dos registros referentes às listas nominativas de habitantes dos anos de 1828, 1835, 1840 e dos inventários post-mortem na segunda metade do século XIX, abordar algumas questões sobre a estrutura de posse de escravos e o comportamento de alguns proprietários com relação ao seu ciclo de vida e a posse de cativos na região dos Campos Gerais do Paraná, mais especificamente em Guarapuava no século XIX. A política de ocupação da localidade promovida pelo Governo Imperial estava voltada para dois aspectos fundamentais: a defesa territorial e a expansão da fronteira.

Assim, a população escrava, apesar de pequena, estava se consolidando a partir das migrações de seus proprietários para a região. Além disso, esses proprietários conseguiam adquirir um maior número de escravos a partir da relação com o seu ciclo de vida, isto é, quanto mais velhos eles ficavam, maiores eram as possibilidades de crescimento na estrutura de posse de cativos. Os escravistas, considerando o período da pesquisa, em sua maioria eram brancos, em torno de $88 \%$, entretanto, verifica-se percentual de proprietários pardos que surpreende, considerando as características da localidade, isto é, com poucos escravos e uma economia de abastecimento.

Finalmente, procuramos verificar essas mesmas características para determinados proprietários de escravos, quando de sua morte, através de seus inventários post-mortem. É importante salientarmos que a amostra aqui desenvolvida apresenta tão somente aqueles proprietários que se inserem nas três listas nominativas. A posse média de escravos demonstra a tendência de aumento na propriedade de cativos, dando-nos condições para que possamos desenvolver a hipótese do ciclo de vida ${ }^{1}$.

${ }^{1}$ A hipótese aqui estabelecida para o ciclo de vida está baseada no trabalho de Renato Leite Marcondes. MARCONDES, Renato Leite. A arte de acumular na economia cafeeira: Vale do Paraíba, século XIX. Lorena, SP: Siciliano, 1998. 


\section{Estrutura de posse de escravos}

A partir das informações registradas nas listas nominativas de habitantes dos anos de 1828, 1835 e 1840, estaremos avaliando o comportamento no tempo da distribuição da escravaria em Guarapuava. A posse média de escravos apresenta crescimento nos períodos selecionados, visto que no ano de 1828 ela era de 2,7 escravos por proprietário, mantendo-se com o mesmo valor para o ano de 1835 e alterando-se para 3,8 escravos por proprietário para o ano de 1840, conforme pode ser verificado pelos dados do quadro 1 .

A razão de masculinidade da população escrava é elevada, considerando-se que grande parte dos escravos era de origem crioula $(85 \%)^{2}$. Essa razão é relevante face às características de sua população, como também dos padrões estabelecidos tanto para o Paraná, quanto para as economias com suas atividades voltadas para o mercado interno. 0 crescimento da população escrava feminina supera o apresentado pela população escrava masculina no período.

De uma posse média em 1828 de 0,9, esta cresce no ano de 1840 para 1,4 , representando um crescimento na posse de escravos de $55,5 \%$, enquanto que a posse média para os homens evolui na ordem de 41\%. Dos 16 proprietários em 1828, 87,5\% possuíam entre 1 a 4 escravos, e apenas dois proprietários possuíam plantéis superiores a 5 escravos. De qualquer forma, o perfil da posse de escravos em Guarapuava demonstra que o padrão dos plantéis era pequeno e que os plantéis menores, de 1 a 4 escravos, detinham $63 \%$ da escravaria, enquanto $37 \%$ se concentravam em apenas dois proprietários.

Quadro 1 - Distribuição da escravaria por proprietário

\begin{tabular}{|c|c|c|c|}
\hline Discriminação & $\mathbf{1 8 2 8}$ & $\mathbf{1 8 3 5}$ & $\mathbf{1 8 4 0}$ \\
\hline Escravos & 43 & 82 & 94 \\
Masculino & 29 & 49 & 59 \\
Feminino & 14 & 33 & 35 \\
RM & 207 & 145 & 168 \\
\hline N $^{\circ}$ de Proprietários & 16 & 30 & 25 \\
\hline Média Plantel & 2,7 & 2,7 & 3,8 \\
Masculino & 1,8 & 1,6 & 2,3 \\
Feminino & 0,9 & 1,1 & 1,4 \\
\hline
\end{tabular}

Fonte: Listas nominativas de habitantes - Guarapuava 1828/1835/1840

${ }^{2}$ Luis Nicolau Parés, em estudo sobre o processo de crioulização no recôncavo baiano na segunda metade do século XVIII, aborda essa questão afirmando que o termo crioulo pode ser entendido como "indivíduo negro de ascendência africana nascido no Brasil”. PARÉS, Luis Nicolau. O processo de crioulização no Recôncavo Baiano (1750-1800). Afro-Ásia, 2005, pp. 87-132. 
Fernando Franco Netto

Para os anos subsequentes, verificam-se alterações importantes quanto à distribuição da posse de escravos, principalmente no ano de 1840, visto que a participação dos proprietários de escravos nos pequenos planteis, em relação ao total, de $87,5 \%$ em 1828 , reduz para $68 \%$.

Apesar disso, o número de escravos apresenta uma maior concentração naqueles proprietários com plantéis maiores, mesmo porque, ao analisarmos os números do quadro 1, verificamos que no ano de $1835,33 \%$ dos escravos estavam nas mãos de apenas 4 proprietários, enquanto que no ano de 1840 esses percentual avança para 57\%, aumentando a concentração em um pequeno número de proprietários, mesmo considerando que o número desses proprietários cresceu para $32 \%$ das propriedades, um crescimento importante se considerar os outros dois anos estudados, que apresentaram números em torno de $13 \%$.

Outro fator interessante é que a posse média de escravos estava se alterando no tempo em função das mudanças que estavam ocorrendo no número de propriedades e no tamanho dos plantéis. Elaboramos, a fim de compreendermos melhor essas modificações, o quadro 2, que apresenta o número de propriedades com relação ao tamanho dos plantéis de escravos, bem como a posse média dessas propriedades. Observa-se que as posses com plantéis de 1 a 4 escravos crescem no período de 1828/1835, porém reduz sua participação no ano de 1840. Já as posses com 5 a 9 escravos apresentam crescimento permanente no período, atingindo uma média de 6,1 escravos no ano de 1840.

Por isso, a média geral pula para 3,8 escravos por propriedade nesse ano, demonstrando que estava havendo um incremento no número de escravos na localidade. Mas isso tudo não altera a tendência das propriedades locais de possuírem entre 1 a 9 escravos em suas propriedades, muito provavelmente em função das características econômicas da região, com suas atividades voltadas para a pecuária e para a pequena lavoura, base de sustentação de sua economia e que caracterizou as populações escravas no Paraná3.

Desta forma, observamos que o movimento da estrutura de posse de escravos em Guarapuava revela uma concentração menor no período 1828/1835 comparativamente ao período 1835/1840. Provavelmente, isso se deve à ocupação inicial da região, que se voltava para a expansão da fronteira face às determinações do Governo, mas que se modifica nos períodos

\footnotetext{
${ }^{3}$ A questão da posse média de escravos ser predominantemente pequena para o Paraná encontramos nos estudos de Horácio Gutierrez. GUTIERREZ, Horácio. Senhores e escravos no Paraná. 1800-1830. Dissertação de Mestrado, USP, São Paulo. 1986.
} 
seguintes, com o fortalecimento da atividade de criação, e que promoveria a ocupação das terras por fazendeiros e tropeiros.

Quadro 2 - Tamanho dos plantéis

\begin{tabular}{|c|c|c|c|c|c|c|}
\hline Plantel Escravos & \multicolumn{2}{|c|}{1828} & \multicolumn{2}{c|}{1835} & \multicolumn{2}{c|}{1840} \\
\hline & Quant. & Média & Quant. & Média & Quant. & Média \\
\hline $1-4$ & 14 & 1,9 & 26 & 2,1 & 17 & 2,3 \\
\hline $5-9$ & 1 & 6 & 3 & 5,3 & 7 & 6,1 \\
\hline 10 ou + & 1 & 10 & 1 & 11 & 1 & 11 \\
\hline Total & 16 & 2,7 & 30 & 2,7 & 25 & 3,8 \\
\hline
\end{tabular}

Fonte: Listas nominativas de habitantes - Guarapuava 1828/1835/1840

Algumas informações dos escravistas são importantes a fim de avaliarmos melhor suas características para os anos selecionados. A maioria dos proprietários é do sexo masculino, portanto achamos dispensável calcularmos a razão de sexo dos proprietários, visto que para o ano de 1828 todos os proprietários são do sexo masculino. No entanto, para o ano de 1835, dos 30 proprietários registrados, apenas 2 são do sexo feminino, enquanto que para o ano de 1840, apenas 1 proprietário é do sexo feminino, de um total de 25 proprietários (quadro 3).

A idade média dos proprietários aumentou gradativamente nos anos selecionados, sendo de 35 anos no ano de 1828, 40 anos para o ano de 1835 e finalmente 42 anos em 1840. Aqui, inferimos uma importante análise na qual a propriedade de escravos estava se concentrando naqueles proprietários, que ao longo de suas vidas acumulavam riqueza, ao mesmo tempo em que a evolução dos proprietários no tempo não configurou uma mobilidade social importante que traduziria em novos proprietários, visto que dos 30 proprietários de escravos no ano de 1830, a grande maioria estava recenseada no ano de 1828.

Para o ano de 1840, o número de proprietários decresce com relação ao ano de 1835, o que para nós poderia ter duas conclusões mais imediatas: primeiramente, problemas com o recenseamento e, em segundo lugar, mobilização para outras localidades não muito distantes de Guarapuava, por exemplo, Palmas, e não inseridas no levantamento quando da elaboração da lista de 1840. 
Fernando Franco Netto

Quadro 3 - Perfil dos proprietários de escravos

\begin{tabular}{|l|c|c|c|c|c|c|c|c|c|}
\hline Discriminação & \multicolumn{3}{|c|}{1828} & \multicolumn{3}{c|}{1835} & \multicolumn{3}{c|}{1840} \\
\hline & M & F & T & M & F & T & M & F & T \\
\hline N $^{\circ}$ Proprietários & 16 & - & 16 & 28 & 2 & 30 & 24 & 1 & 25 \\
Participação \% & $100 \%$ & - & $100 \%$ & $93 \%$ & $7 \%$ & $100 \%$ & $96 \%$ & $4 \%$ & $100 \%$ \\
Idade média & 35 & - & 35 & 40 & - & 40 & 42 & - & 42 \\
\hline Estado Conjugal: & & & & & & & & & \\
Casado (\%) & $73 \%$ & - & $73 \%$ & $82 \%$ & - & $82 \%$ & $74 \%$ & - & $74 \%$ \\
Solteiro (\%) & $27 \%$ & - & $27 \%$ & $18 \%$ & - & $18 \%$ & $26 \%$ & - & $26 \%$ \\
Viúvo (\%) & - & - & - & - & - & - & - & - & - \\
\hline Cor Proprietário: & & & & & & & & & \\
Branco (\%) & & & $80 \%$ & & & $88 \%$ & & & $95 \%$ \\
Pardo (\%) & & & $20 \%$ & & & $12 \%$ & & & $5 \%$ \\
\hline
\end{tabular}

Fonte: Listas nominativas de habitantes - Guarapuava 1828/1835/1840

Da mesma forma, a participação dos proprietários casados aumenta no período $1828 / 1835$, passando de um porcentual de $73 \%$ para $82 \%$, o que reflete na participação dos proprietários solteiros que decresce de $27 \%$ para $18 \%$ no mesmo período. Entretanto, já no período 1835/1840, ocorre o inverso quanto à participação dos proprietários casados e solteiros, sendo $74 \%$ para os casados e $26 \%$ para os solteiros. O que podemos inferir nesses resultados é que, para o ano de 1835 houve muitos proprietários sem idade, o que provavelmente afetou o seu resultado, sendo a tendência geral aquela apresentada nos anos de 1828 e 1840. Isso também é reflexo da política de ocupação, promovendo a migração de pessoas mais jovens para a localidade a fim de desenvolverem suas atividades.

A condição dos proprietários levando em conta sua cor revela que somente os proprietários de cor branca e parda fazem parte do levantamento, pois $80 \%$ são brancos no ano de 1828 e $20 \%$ são pardos. Para o ano de 1835 , esse porcentual se altera para $88 \%$ para os brancos e para $12 \%$ para os pardos, finalmente, para o ano de 1840 , 95\% são brancos e 5\% pardos. É importante ressaltar que observamos algumas dificuldades no levantamento dos dados, visto que alguns proprietários, em determinado ano eram definidos como pardos, sendo sua cor modificada nos anos seguintes. Não queremos afirmar com isso que, em função dessas alterações, o porcentual de proprietários brancos e pardos seria mais homogêneo. 
Em sua pesquisa sobre os significados da liberdade no sudeste, Hebe Matos procura analisar a cor como possível significado de liberdade. ${ }^{4}$ Dessa forma, e considerando as especificidades de Guarapuava, parece que essa característica - o ser pardo - poderia representar "sinônimo de escravo ou liberto". Ser branco possuía um significado muito importante no contexto social, pois representava a condição de liberdade. ${ }^{5}$ Fatores como a falta de registro ou mesmo o sumiço do registro da cor é recorrente ao se debruçar nos registros civis ou processos-crime. Matos sugere que esse acontecimento "se deu ainda por volta da metade do século XIX". O problema da cor tomava seu lugar na sociedade da época a partir da definição de lugares sociais "nos quais etnia e condição estavam indissociadamente ligados". Para tanto, Matos sugere que a cor "era um signo de cidadania na sociedade imperial, para a qual apenas a liberdade era precondição". ${ }^{6}$

Em outro estudo, Roberto Guedes Ferreira, ao pesquisar sobre escravidão e cor nos censos de Porto Feliz no século XIX, afirma que a escravidão "tornou os livres mais brancos, os escravos mais negros e os agregados mais pardos" ". Assim, a cor representava, de certa forma, um distanciamento da condição escrava. Outro fator importante seria com relação de quem fazia o registro, pois de acordo com o autor "nem sempre há consonância entre os termos utilizados por autoridades que elaboraram os mapas e os recenseadores que fizeram as listas". No caso de Porto Feliz, os dados indicam uma "caracterização pontual e personalizada nas listas, uma vez que as mesmas pessoas/famílias frequentemente mudavam de cor". Dessa forma, o pesquisador analisa tal fato como possibilidades dos recenseadores com relação a determinadas situações e que poderiam interferir nos registros, bem como "remete ao lugar social conforme as circunstâncias sociais".

Em Guarapuava, tais situações poderiam estar ocorrendo, seja em função da sugestão apresentada pelos autores com relação aos lugares sociais, seja pelo poder dos recenseadores de alterar tais registros em função da posição do chefe do domicílio.

No quadro 4, apresentamos os números referentes à posse média de escravos segundo as faixas etárias de seus proprietários. Observamos que a

${ }^{4}$ MATTOS, Hebe Maria. Das cores do silêncio: os significados da liberdade no Sudeste escravista, Brasil século XIX. Rio de Janeiro: Nova Fronteira, 1998.

${ }^{5}$ Ibidem.

${ }^{6}$ Ibidem.

${ }^{7}$ GUDES, Roberto. Escravidão e cor nos Censos de Porto Feliz (São Paulo, Século XIX). Santa Cruz, Ilhéus, Bahia. Cadernos de Ciências Humanas - Especiaria. V.10, n. 18, jul-dez, 2007, p. 489-518. 
posse média evoluiu em todo o período, principalmente para o último ano analisado, função provável da expansão da atividade da pecuária. Ao analisarmos por cada ano selecionado, verificamos que a concentração dos proprietários para o ano de 1828 se dava na faixa etária mais jovem, isto é, entre 20-39 anos, pois essa faixa detinha $69 \%$ da posse de escravos.

O restante estava concentrado na faixa etária de 50-59 anos com 19\%. Finalmente, acrescentamos que havia apenas 1 proprietário na faixa etária mediana, ao mesmo tempo em que observamos a presença de 1 absenteísta fazendo parte da lista de proprietários desse ano.

Para o ano de 1835, verificamos que os proprietários na faixa etária de 20-39 anos reduzem seus porcentuais em 50\%, principalmente em função da participação dos proprietários classificados como absenteístas, que cresce muito no período, enquanto que, para as outras faixas etárias, o perfil dos proprietários permanece praticamente o mesmo do ano de 1828. Importante ressaltar o crescimento que ocorre na faixa etária de 30-39 anos, que passa de 7 para 12 proprietários no período de 1828/1835, significando um crescimento de $71 \%$.

Já para o ano de 1840, verificamos algumas alterações importantes na distribuição dos proprietários por faixas etárias, visto que se eleva a concentração para a faixa etária considerada mediana, com uma participação de $36 \%$. Observamos também que o número de proprietários absenteístas cai muito no período, dando-nos a hipótese de que os proprietários já estavam determinados a residirem em suas próprias posses.

Com relação à posse média de escravos, os proprietários na faixa etária de 20-29 anos detinham 2,5 escravos no ano de 1828. Para os anos seguintes, o comportamento da escravaria oscilou bastante, visto que no ano de 1835 esse número cai para 1,6, crescendo posteriormente para 3,3 escravos no ano de 1840. 
Posse de cativos e a hipótese do ciclo de vida - Guarapuava - Século xix

Quadro 4 - Perfil da escravaria por faixa etária dos proprietários

\begin{tabular}{|c|c|c|c|}
\hline Faixa etária & 1828 & 1835 & 1840 \\
\hline 20-29 & 10 & 5 & 10 \\
\hline Masculino & 7 & 3 & 7 \\
\hline Feminino & 3 & 2 & 3 \\
\hline $\mathrm{RM}$ & 233 & 150 & 233 \\
\hline $30-39$ & 12 & 37 & 23 \\
\hline Masculino & 6 & 21 & 16 \\
\hline Feminino & 6 & 16 & 7 \\
\hline RM & 100 & 131 & 228 \\
\hline 40-49 & 10 & 2 & 26 \\
\hline Masculino & 7 & 1 & 18 \\
\hline Feminino & 3 & 1 & 8 \\
\hline $\mathrm{RM}$ & 233 & 100 & 225 \\
\hline $50-59$ & 8 & 20 & 22 \\
\hline Masculino & 6 & 11 & 12 \\
\hline Feminino & 2 & 9 & 10 \\
\hline $\mathrm{RM}$ & 300 & 122 & 120 \\
\hline $60-69$ & - & 4 & 4 \\
\hline Masculino & - & 3 & 1 \\
\hline Feminino & - & 1 & 3 \\
\hline $\mathrm{RM}$ & - & 300 & 33 \\
\hline Absenteístas & 3 & 14 & 9 \\
\hline Masculino & 3 & 11 & 5 \\
\hline Feminino & - & 3 & 4 \\
\hline $\mathrm{RM}$ & - & 367 & 125 \\
\hline Total & 43 & 82 & 94 \\
\hline Masculino & 29 & 49 & 59 \\
\hline Feminino & 14 & 33 & 35 \\
\hline $\mathrm{RM}$ & 207 & 148 & 169 \\
\hline
\end{tabular}

Fonte: Listas nominativas de habitantes - Guarapuava 1828/1835/1840

A questão referente à concentração dos proprietários na faixa etária de 20-39 anos, principalmente nos dois primeiros anos analisados, tem sua influência na política de ocupação adotada pelo Governo, que trouxe como estímulo a mobilidade social com a migração de novos proprietários. Já para o ano de 1840, verificamos que o perfil dos proprietários se modifica, visto que provavelmente aqueles que nos anos anteriores se deslocaram para a região já estavam consolidando seu patrimônio. 
Interessante seriam, a fim de verificarmos a questão acima, os possíveis registros dos movimentos migratórios, o que não faz parte dessa pesquisa, mas que traria informações importantes sobre a condição dos proprietários.

Verificamos que a faixa etária jovem (20-39 anos), possui em média 2,2 escravos no período de 1828-1835, elevando-se para 3,5 no ano de 1840. Quanto ao ano de 1840, tais proprietários possuíam em média 2,9 escravos, para uma amostragem mais significativa. Para a faixa etária de 50-59 anos verificamos a maior média dos plantéis.

Quando consideramos a faixa etária mais idosa, observamos um número médio de escravos abaixo das outras faixas etárias, dando-nos inicialmente as mesmas conclusões da hipótese do ciclo de vida. Finalmente, ao verificarmos o número médio de escravos, considerando os proprietários absenteístas, apesar de o número de escravos reduzir significativamente no ano de 1835, observamos que a posse de escravos tende a ser elevada nos anos selecionados. Como a economia local estava se consolidando na atividade da pecuária, podemos observar os efeitos dessa atividade em função do crescimento médio da escravaria no período, que passa de 2,7 para 3,8 escravos por proprietário.

Quanto à ocupação dos escravistas, podemos observar que, com exceção do ano de 1828, a maioria deles estava concentrada nas atividades voltadas para a pecuária e para a criação, participando com $77 \%$ e $48 \%$ para os anos de 1835 e 1840 respectivamente, conforme quadro 5.

Cabe ressaltar que grande parte dos descritos como "militares", dos comerciantes e do padre local, possuía terras para a criação de animais ${ }^{8}$. Não devemos deixar de considerar que a participação dos militares é crescente, visto a necessidade do Governo em proteger a localidade de possíveis ataques contra a fronteira. A metodologia ${ }^{9}$ adotada para a inclusão do termo "novos habitantes" no ano de 1828 considera aqueles indivíduos que na lista estão com suas profissões não registradas, pois acreditamos que essas pessoas estavam chegando à localidade a fim de constituírem novos domicílios, tanto que, na lista seguinte, todos eles possuíam profissão registrada.

\footnotetext{
${ }^{8}$ Com relação a isso, encontramos dados de atividades secundárias para esses proprietários na lista nominativa do ano de 1835 e que registram que os mesmos tinham como segunda atividade a criação de animais. Da mesma forma pelos processos de inventários dos proprietários verificamos a confirmação dessas atividades.

${ }^{9}$ Tomamos a liberdade de inserir a metodologia empregada por José Flávio Motta em seu estudo sobre a estrutura de posse de escravos sobre a localidade de Bananal. MOTTA, José Flávio. Corpos escravos, vontades livres: posse de cativos e família escrava em Bananal 1801-1829. FAPESP. São Paulo: Annablume. 1999.
} 
Quadro 5 - Ocupação dos proprietários de escravos

\begin{tabular}{|l|c|c|c|c|c|c|}
\hline \multicolumn{1}{|c|}{ Ocupação } & \multicolumn{2}{c|}{$\mathbf{1 8 2 8}$} & \multicolumn{2}{c|}{$\mathbf{1 8 3 5}$} & \multicolumn{2}{c|}{1840} \\
\hline & Quant. & $\mathbf{\%}$ & Quant. & \% & Quant. & \% \\
\hline Militar & 1 & $6,2 \%$ & 2 & $6,8 \%$ & 5 & $20,0 \%$ \\
\hline Alferes & 1 & $6,2 \%$ & 1 & $3,3 \%$ & - & - \\
\hline Fazendeiro & 1 & $6,2 \%$ & 10 & $33,3 \%$ & 6 & $24,0 \%$ \\
\hline Comerciante & - & - & 1 & $3,3 \%$ & 1 & $4,0 \%$ \\
\hline Criador & - & - & 13 & $43,4 \%$ & 6 & $24,0 \%$ \\
\hline Juiz & - & - & 1 & $3,3 \%$ & - & - \\
\hline Carpinteiro & - & - & 1 & $3,3 \%$ & - & - \\
\hline Lavrador & - & - & - & - & 3 & $12,0 \%$ \\
\hline Eclesiástico & - & - & 1 & $3,3 \%$ & 1 & $4,0 \%$ \\
\hline Sapateiro & - & - & - & - & 1 & $4,0 \%$ \\
\hline Capataz & - & - & - & - & 1 & $4,0 \%$ \\
\hline Inspetor & - & - & - & - & 1 & $4,0 \%$ \\
\hline Novos Habitantes & 13 & $81,4 \%$ & - & - & - & - \\
\hline Total & 16 & $100,0 \%$ & 30 & $100,0 \%$ & 25 & $100,0 \%$ \\
\hline
\end{tabular}

Fonte: Listas nominativas de habitantes - Guarapuava 1828/1835/1840

O número de outras atividades, mesmo sendo pequeno, cresce na localidade, demonstrando certa diversificação nas atividades locais quanto à dinâmica econômica, significando concentração menor na propriedade de escravos.

É interessante notarmos a queda no número de proprietários para as atividades relacionadas com a fazenda e com a criação nos anos de 18351840. Além de alguns movimentos migratórios para outras localidades, levantamos a hipótese de que alguns proprietários absenteístas deixaram a localidade talvez em função de suas dificuldades de administrar as fazendas. Pelo cruzamento das listas de 1835 e de 1840,5 proprietários absenteístas que estavam incluídos na lista de 1835 não aparecem mais na lista de 1840 .

Avaliando a faixa etária dos proprietários e, considerando a posse de cativos por faixa etária - quadro 6 -, verifica-se que a grande maioria dos proprietários possuía um número maior de homens em seus plantéis. A razão de mais taxa de masculinidade para a faixa etária de $20-29$ anos se manteve em 233 para os anos de 1828 e 1840, apenas no ano de 1835 é que o plantel foi um pouco mais homogêneo. 
Fernando Franco Netto

Vários são os trabalhos que identificam o indicador de taxa de masculinidade alta nos plantéis, principalmente quando esses plantéis eram abastecidos por africanos. Manolo Florentino e José Roberto Góes, ao pesquisarem sobre as propriedades no Rio de Janeiro na segunda metade do século XVIII e primeira metade do XIX, afirmam que "os homens representavam entre $55 \%$ e dois terços de toda a escravaria em todos os intervalos de tempo"10. Portanto, esses números indicavam que o percentual de homens nas propriedades sempre foi superior ao número de mulheres, principalmente quando o abastecimento via tráfico era mais intenso.

Entretanto, os números revelam que quando os plantéis eram menores, isto é, menos de 9 escravos, "a taxa de masculinidade de seus plantéis tendia a diminuir em direção a um maior equilíbrio entre homens e mulheres". ${ }^{11}$ Esses indicadores podem supor que tais propriedades teriam menos acesso ao mercado do tráfico em função de suas possibilidades econômicas.

Contudo, o intrigante para a localidade de Guarapuava está exatamente no abastecimento de seus plantéis, isto é, são escravos preferencialmente crioulos, ao mesmo tempo em que seus plantéis são pequenos. Acreditamos também que, conforme hipótese nos estudos de Florentino e Góes, as possibilidades dos proprietários de escravos participarem do mercado de homens eram muito pequenas em função do tamanho do capital que deveria ser aplicado na compra dos escravos.

Em todos os períodos analisados a razão de masculinidade é importante e significativa, considerando todas as faixas etárias dos proprietários. Ao estudarmos o perfil da escravaria por faixas etárias, verificamos que, apesar do número expressivo de crianças no ano de 1828 , a tendência dos plantéis foi de concentração na faixa etária produtiva e com muito pouca participação da faixa etária considerada como idosa. Isso significa que o comportamento dos proprietários estava sendo dirigido para manter um perfil de escravaria que fosse o mais produtivo possível.

10 MANOLO, Florentino, GÓES, José Roberto. A paz das senzalas: famílias escravas e tráfico atlântico, Rio de Janeiro, c.1790-1850. Rio de Janeiro: Civilização Brasileira, 1997.

11 Ibidem. 
Posse de cativos e a hipótese do ciclo de vida - Guarapuava - Século xix

Quadro 6 - Perfil dos proprietários por faixa etária e por faixa etária dos plantéis

\begin{tabular}{|c|c|c|c|c|c|c|c|c|c|}
\hline \multirow[t]{2}{*}{ Descrição } & \multicolumn{3}{|c|}{1828} & \multicolumn{3}{|c|}{1835} & \multicolumn{3}{|c|}{1840} \\
\hline & $\mathbf{M}$ & $\mathbf{F}$ & $\mathrm{T}$ & $\mathbf{M}$ & $\mathbf{F}$ & $\mathbf{T}$ & $\mathbf{M}$ & $\mathbf{F}$ & $\mathbf{T}$ \\
\hline Proprietários 20-29 & & & & & & & & & \\
\hline $0-14$ & 2 & 2 & 4 & 1 & - & 1 & 2 & 1 & 3 \\
\hline $15-49$ & 5 & 1 & 6 & 1 & 2 & 3 & 5 & 2 & 7 \\
\hline $50 \mathrm{ou}+$ & - & - & - & 1 & - & 1 & - & - & - \\
\hline Proprietários 30-39 & & & & & & & & & \\
\hline $0-14$ & 4 & 3 & 7 & 6 & 5 & 11 & 5 & 1 & $\begin{array}{c}0 \\
17\end{array}$ \\
\hline $15-49$ & 2 & 2 & 4 & 15 & 11 & 26 & 11 & 6 & 17 \\
\hline $50 \mathrm{ou}+$ & - & 1 & 1 & - & - & - & - & - & \\
\hline Proprietários 40-49 & & & & & & & & & \\
\hline $0-14$ & 5 & 1 & 6 & - & - & - & 5 & 2 & 7 \\
\hline $15-49$ & 2 & 2 & 4 & 1 & 1 & 2 & 12 & 6 & 18 \\
\hline $50 \mathrm{ou}+$ & - & - & - & - & - & - & - & 1 & 1 \\
\hline Proprietários 50-59 & & & & & & & & & \\
\hline $0-14$ & 2 & 1 & 3 & 4 & 2 & 6 & 3 & 3 & 6 \\
\hline $15-49$ & 4 & 1 & 5 & 7 & 7 & 14 & 9 & 5 & 14 \\
\hline $50 \mathrm{ou}+$ & - & - & - & - & - & - & - & 2 & 2 \\
\hline Proprietários 60-69 & & & & & & & & & \\
\hline $0-14$ & - & - & - & 2 & 1 & 3 & - & - & - \\
\hline $15-49$ & - & - & - & 1 & - & 1 & 1 & 3 & 4 \\
\hline $50 \mathrm{ou}+$ & - & - & - & - & - & - & - & - & - \\
\hline Absenteístas & & & & & & & & & \\
\hline $0-14$ & - & - & - & 3 & - & 3 & 2 & 1 & 3 \\
\hline $15-49$ & 3 & - & 3 & 8 & 3 & 11 & 3 & 3 & 6 \\
\hline $50 \mathrm{ou}+$ & - & - & - & - & - & - & - & - & - \\
\hline Total & & & & & & & & & \\
\hline $0-14$ & 13 & 8 & 21 & 16 & 7 & 23 & 17 & 8 & 25 \\
\hline $15-49$ & 16 & 5 & 21 & 32 & 26 & 58 & 41 & 25 & 66 \\
\hline $50 \mathrm{ou}+$ & - & 1 & 1 & 1 & - & 1 & - & 3 & 3 \\
\hline
\end{tabular}

Fonte: Listas nominativas de habitantes - Guarapuava 1828/1835/1840

\section{Evolução dos proprietários de escravos}

Nesta parte do trabalho avaliaremos os proprietários de escravos que participam das três listas nominativas aqui pesquisadas, ou seja, para os anos de 1828, 1835 e 1840. Estudaremos sua evolução e como a hipótese do ciclo de vida faz-nos compreender melhor a composição da riqueza e de estabilidade familiar entre aqueles proprietários. Avaliaremos também 5 proprietários no momento de seu falecimento, incluindo, portanto, a 
análise de seus inventários, a fim de podermos fazer alguns comparativos importantes quanto ao recorte longitudinal de suas vidas.

Os proprietários analisados representam $50 \%$ para a amostra de 1828 , $23 \%$ para o ano de 1835 e $44 \%$ para o ano de 1840 . Enquanto isso, a escravaria representa respectivamente $53,5 \%, 30,5 \%$ e $46,8 \%$ do total dos plantéis. $\mathrm{Na}$ amostra, a predominância é de proprietários do sexo masculino, destes, 16 proprietários são casados, perfazendo $76 \%, 3$ proprietários solteiros totalizando $14 \%$ e 2 proprietários não tinham o seu estado civil registrado.

A posse média de escravos desses proprietários evoluiu no tempo. Se em 1828 era de 2,9 escravos por proprietário, atinge a média 4,0 em 1840, com crescimento na ordem de $38 \%$. Ao consideramos o ano de 1835 , a média de escravos por proprietário foi de 3,6, com um acréscimo à lista de 1828 de $24 \%$.

A distribuição da escravaria é analisada no quadro 7. Verifica-se que a preferência por escravos do sexo masculino é constante para o período, apresentando uma razão de masculinidade elevada em seus plantéis. 0 escravo do sexo masculino sempre superou em média as escravas nos plantéis, apesar do crescimento relativo muito mais expressivo das mulheres escravas, que tiveram no período de 1828/1840 uma evolução no número médio de $75 \%$, enquanto para os homens esse percentual foi de 19\%. Observa-se, portanto, que os proprietários estavam acumulando um volume maior da mão de obra escrava feminina. Apesar disso, a razão de masculinidade nos plantéis era elevada, o que pode ser observado no próprio quadro.

Quadro 7 - Distribuição da escravaria por proprietário

\begin{tabular}{|l|c|c|c|}
\hline \multicolumn{1}{|c|}{ Discriminação } & $\mathbf{1 8 2 8}$ & $\mathbf{1 8 3 0}$ & $\mathbf{1 8 4 0}$ \\
\hline Escravos & 23 & 25 & 44 \\
Masculino & 17 & 15 & 28 \\
Feminino & 6 & 10 & 16 \\
RM & 283 & 150 & 175 \\
\hline N $^{\circ}$ Proprietários & 8 & 7 & 11 \\
\hline Média Plantel & 2,9 & 3,6 & 4,0 \\
Masculino & 2,1 & 2,1 & 2,5 \\
Feminino & 0,8 & 1,4 & 1,4 \\
\hline
\end{tabular}

Fonte: Listas nominativas de habitantes - Guarapuava 1828/1835/1840

Importante ressaltar que, dos onze escravistas selecionados na lista de 1840, apenas oito possuíam escravos em 1828 e sete na lista de 1835 . A hipótese que admitimos aqui é de que esses proprietários estavam acumulando cativos concomitantemente ao aumento de suas riquezas. Ao mesmo 
tempo, verificamos dois proprietários na lista de 1828 que possuíam escravos e, por algum motivo, esses escravos não estão listados no ano de 1835.

Ao analisarmos os números dos proprietários selecionados com o total dos proprietários em cada ano, podemos tirar algumas conclusões: o número médio de escravos se torna mais significativo para os proprietários da amostra, pois apresentam valores superiores àqueles apresentados pelo total dos proprietários. Em 1828, a média de escravos, considerando a amostra, é de 2,9, enquanto para o total dos proprietários é de 2,7. Para os anos de 1835 e 1840, esses números são mais expressivos, visto que se situam ao redor de 3,5 e 4,0 para os proprietários da amostra, enquanto que para o total dos proprietários eles são de 2,7 e 3,8.

O quadro 8 mostra o número médio de escravos por ocupação dos proprietários. Identificamos alguns importantes indicadores, visto as características da economia local. A distribuição, a partir do ano de 1828, indica uma diversificação das atividades dos proprietários, mesmo porque não foram registradas as atividades de 6 proprietários, os quais foram considerados como "novos habitantes". Entretanto, alguns deles já apresentavam como segunda atividade a criação de animais.

Do total de escravos no ano de $1840,54 \%$ estavam concentrados naqueles proprietários com ocupação definida de criação de animais, $29 \%$ era posse de militares e o restante da escravaria estava distribuída da seguinte forma: 1 comerciante, 2 lavradores e 1 inspetor, perfazendo $16 \%$ da escravaria. Para os anos de 1828 e 1835, há uma maior concentração de escravos na propriedade de 1 militar, que possuía 43\% da escravaria em 1828 e 44\% em 1835. Entretanto, devemos reafirmar que esse proprietário tinha como prática a criação de animais, pois um de seus domicílios estava caracterizado como absenteísta.

Quadro 8 - Profissão dos proprietários e número médio de escravos

\begin{tabular}{|l|c|c|c|c|c|c|}
\hline \multicolumn{1}{|c|}{ Profissão } & \multicolumn{2}{c|}{1828} & \multicolumn{2}{c|}{1835} & \multicolumn{2}{c|}{1840} \\
\hline & Quant. & Escravos & Quant. & Escravos & Quant. & Escravos \\
\hline Militar & 1 & 10 & 1 & 11 & 2 & 13 \\
\hline Comerciante & - & - & 1 & 1 & 1 & 2 \\
\hline Criador & - & - & 4 & 7 & 3 & 13 \\
\hline Fazendeiro & - & - & - & - & 2 & 11 \\
\hline Lavrador & - & - & - & - & 2 & 3 \\
\hline Inspetor & - & - & 1 & 6 & - & - \\
\hline Alferes & 1 & 4 & - & - & - & - \\
\hline Novos Habitantes & 6 & 9 & - & - & 1 & 2 \\
\hline Total & 8 & 23 & 7 & 25 & 11 & 44 \\
\hline
\end{tabular}

Fonte: Listas nominativas de habitantes - Guarapuava 1828/1835/1840 
Quanto às características da escravaria, considerando a faixa etária dos proprietários, verificamos alguns dados interessantes no quadro 9. Em 1840, as faixas etárias consideradas mais jovens, isto é, dos 20 aos 39 anos, apresenta uma média de 3,7 escravos por proprietário, enquanto isso, a faixa etária de 50-59 anos, considerada como a faixa de estabilidade patrimonial para o proprietário, apresenta uma média de 9,0. Finalmente, a faixa etária idosa apresenta a menor média de posse de escravos.

Ao verificarmos os outros períodos, observamos essa dinâmica entre as faixas etárias dos proprietários, visto que os proprietários que no ano de 1840 estavam na faixa etária dos 50 anos, nos anos anteriores estavam fazendo parte da faixa etária dos 40 anos, o que pode ser observado principalmente no ano de 1828.

Quadro 9 - Características da escravaria por faixa etária do proprietário

\begin{tabular}{|l|c|c|c|}
\hline \multicolumn{1}{|c|}{ Faixa Etária } & $\mathbf{1 8 2 8}$ & $\mathbf{1 8 3 5}$ & $\mathbf{1 8 4 0}$ \\
\hline $20-29$ & 1 & - & - \\
Masculino & 4 & - & - \\
Feminino & - & - & - \\
RM & - & - & 4 \\
\hline $30-39$ & 4 & 2 & 11 \\
Masculino & 1 & 3 & 4 \\
Feminino & 3 & 1 & 275 \\
RM & 33 & 300 & 3 \\
\hline $40-49$ & 1 & 1 & 5 \\
Masculino & 7 & 1 & 2 \\
Feminino & 3 & 1 & 250 \\
RM & 233 & 100 & 2 \\
\hline $50-59$ & 2 & 3 & 11 \\
Masculino & 5 & 11 & 7 \\
Feminino & - & 7 & 220 \\
RM & - & 157 & 2 \\
\hline $60-69$ & - & 1 & 1 \\
Masculino & - & - & 3 \\
Feminino & - & 1 & 33 \\
RM & - & - & 11 \\
\hline Total & 8 & 15 & 28 \\
Masculino & 17 & 150 & 16 \\
Feminino & 283 & 75 \\
RM & $n$ & 10 & \\
\hline
\end{tabular}

Fonte: Listas nominativas de habitantes - Guaraptuava 1828/1835/1840 
Da mesma forma, podemos inferir esses resultados quando analisamos a faixa etária de 20-29 anos, pois, para os anos de 1835 e 1840 não há nenhum registro de proprietários e de escravos. Outro dado interessante é com relação à evolução da posse média de escravos nas faixas etárias de 2039 anos, que passou de uma média de 1,6 escravos no ano de 1828, para uma média de 2,0 em 1835, e, finalmente, em 1840, o número médio foi de 3,7.

Isso provavelmente está relacionado com as características iniciais dos mais jovens de menor condição em adquirir escravos. Também verificamos, para as diversas faixas etárias dos proprietários, uma alta razão de masculinidade nos plantéis, com diferenças importantes apenas em dois momentos específicos que se relacionam com a faixa etária de 30-39 anos para o ano de 1828, e para a faixa etária de 60-69 anos no ano de 1840 .

Ao considerarmos a posse cativa nos diversos anos selecionados, verificamos que a média de cativos cresce no período. Analisando os proprietários em conjunto, damo-nos conta de que a posse média de cativos cresceu de uma forma constante nos três anos selecionados. Assim, podemos inferir que a hipótese do ciclo de vida é confirmada quando analisamos esses proprietários nas diversas fases de suas vidas.

Ao avaliarmos individualmente os proprietários, a hipótese do ciclo de vida se insere nas características da maioria deles, por isso elaboramos o quadro 10, que discrimina esses proprietários, sua idade no ano de 1828, o estado civil de cada um e o número de escravos para cada ano.

Apenas 1 proprietário dos 11 aqui selecionados apresentou queda na posse de escravos, sendo que três proprietários mantiveram seus plantéis a partir do ano de 1835. Importante avaliarmos, pelos dados da tabela, o crescimento da escravaria, principalmente a partir do ano de 1840, consequência provável do fortalecimento das atividades econômicas da localidade. Dados sobre Guarapuava e região demonstram o aquecimento de sua economia basicamente em função das estatísticas elaboradas pelos responsáveis do Relatório da Província do Paraná no ano de 1859, que apresenta o mapa das fazendas de criação e o número de animais. Nesse ano, Guarapuava possuía 72 fazendas de criação, o que representava $46,1 \%$ de todas as propriedades na Província. Com relação ao número de animais, o total apresentado pela localidade foi de 112.880 , representando $49,7 \% .{ }^{12}$

Dessa forma, percebe-se que a região estava desenvolvendo suas atividades com base na pecuária, concomitantemente com a comercialização do

${ }^{12}$ FRANCO NETTO, Fernando. Senhores e escravos no Paraná Provincial: os padrões de riqueza em Guarapuava (1850/1880). Guarapuava: Unicentro, 2011. 
gado e a lavoura de alimentos. Os dados confirmam a evolução no período da segunda metade do XIX da economia campeira e que poderia justificar os investimentos dos proprietários de escravos no crescimento de suas posses.

Quadro 10 - Evolução da posse de escravos - primeira metade século XIX

\begin{tabular}{|l|c|c|c|c|c|}
\hline \multicolumn{1}{|c|}{ Proprietários } & \multicolumn{2}{|c|}{ Característica } & 1828 & 1835 & 1840 \\
\hline & $\begin{array}{c}\text { Idade } \\
1828\end{array}$ & $\begin{array}{c}\text { Estado } \\
\text { civil }\end{array}$ & & & \\
\hline Antônio Rocha Loures & 58 & Casado & 10 & 11 & 11 \\
\hline Silvério Antonio Oliveira & 53 & Casado & - & 1 & 2 \\
\hline Jerônimo José Caldas & 53 & Casado & 1 & 1 & 2 \\
\hline Jacob Dias Oliveira & 33 & Casado & 1 & 2 & 4 \\
\hline Pedro José Pereira & 22 & Solteiro & - & - & 2 \\
\hline Antonio José Souza & 30 & Casado & 1 & - & 1 \\
\hline João C. Assunção & 31 & Casado & 1 & 2 & 2 \\
\hline José Siqueira Cortes & 24 & Solteiro & 4 & 2 & 2 \\
\hline Joaquim Batista Santos & 34 & Casado & 1 & - & 2 \\
\hline Antonio Sá Camargo & 20 & Solteiro & - & - & 9 \\
\hline Manoel Mendes Araujo & 50 & Solteiro & 4 & 6 & 7 \\
\hline
\end{tabular}

Fonte: Listas nominativas de habitantes - Guarapuava 1828/1835/1840

É importante avaliarmos pelos dados do quadro o crescimento da escravaria, principalmente a partir do ano de 1840, consequência provável do fortalecimento das atividades econômicas da localidade.

Destacamos no trabalho alguns proprietários que faleceram em períodos após 1840, com o intuito de acompanhar suas trajetórias a partir de seus inventários. 0 período em que esses inventários foram produzidos inclui as décadas de 1850, 1860 e 1870, período esse que influenciou muito a política e as formas de aquisição de cativos pelos proprietários, tendo em vista as peculiaridades do mercado de escravos, o fim do tráfico e também as leis internas que dificultavam a posse de escravos.

Apenas um proprietário está incluído nas listas nominativas nos anos de 1828,1835 e 1840 . Os demais, apesar de não fazerem parte de todas as listas, estão registrados nas listas de 1835 e 1840. A idade média dos proprietários, quando de seu falecimento, aproxima-se de 68 anos, ao mesmo tempo em que eles atingiam o máximo em termos de posse de escravos.

Considerando a atividade principal de cada um deles, 3 proprietários se ocupavam da criação de animais, 1 era eclesiástico e 1 era militar. Apesar 
disso e verificando suas posses, observamos que aqueles que não tinham declarado como principal atividade a criação de animais tinham como atividade secundária essa atividade. Ao verificarmos seus bens no momento da pesquisa nos inventários, observamos o padrão de suas posses em Réis.

Quadro 11 - Evolução da escravaria e padrão de riqueza - proprietários selecionados

\begin{tabular}{|l|c|c|c|c|c|c|c|}
\hline \multicolumn{1}{|c|}{ Proprietário } & $\begin{array}{c}\text { Idade } \\
\text { Inventário }\end{array}$ & 1828 & 1835 & 1840 & \multicolumn{2}{c|}{ Inventário } & $\begin{array}{c}\text { Riqueza } \\
\text { em Réis }\end{array}$ \\
\hline & & & & & Ano & Escravo & \\
\hline José S. Cortes & 55 & 4 & 2 & 2 & 1859 & 17 & $92: 013 \$ 000$ \\
\hline Ponciano J. Araújo & 50 & - & 5 & 5 & 1854 & 5 & $57: 192 \$ 000$ \\
\hline Bernardino J. Lacerda & 68 & - & 4 & 3 & 1868 & 22 & $136: 483 \$ 000$ \\
\hline Hermenegildo Araújo & 83 & - & 1 & 1 & 1877 & 4 & $19: 465 \$ 844$ \\
\hline Joaquim J. Lacerda & 75 & - & 3 & 3 & 1877 & 8 & $51: 471 \$ 585$ \\
\hline
\end{tabular}

Fonte: Processos de Inventário

Pelo quadro acima, pode-se verificar a evolução da escravaria de cada proprietário e seu crescimento ao longo do tempo. A posse de cativos para esses proprietários evoluiu de acordo com o seu ciclo de vida, e mesmo considerando que alguns deles mantiveram o mesmo número de cativos em relação aos anos anteriores, o valor de suas posses, quando do arrolamento de seus bens, mostra-nos um importante patrimônio adquirido pelos anos de sua vida.

Apesar de um número reduzido de propriedades, sugere-se que a hipótese do ciclo de vida estivesse acontecendo na localidade, o que pode ser confirmado, no momento da avaliação de seus bens realizada oficialmente através dos inventários post-mortem. Para uma região onde suas atividades eram predominantemente voltadas para o mercado interno, são expressivos os números apresentados por esses inventários, se compararmos com aquelas regiões ${ }^{13}$ já estudadas e voltadas à produção para o mercado externo, considerando a média de escravos em posse.

${ }^{13}$ Diversos estudos sobre a distribuição da riqueza por proprietários de escravos já foram realizados e citamos alguns deles como o de MELLO, Zélia M.Cardoso de. Metamorfoses da riqueza: São Paulo, 18451895. São Paulo: Hucitec, 1985. MARCONDES, Renato Leite. A arte de acumular na economia cafeeira: Vale do Paraíba, século XIX. Lorena, SP: Siciliano, 1998. LIMA, Carlos Alberto Medeiros. Escravidão e famílias livres: o caso dos artesãos da cidade do Rio de Janeiro 1797/1845. Cadernos do laboratório interdisciplinar de pesquisas em História Social. Rio de Janeiro, IFCS/UFRJ. N¹, 1995. FARIA, Sheila Siqueira de Castro. A colônia em movimento: fortuna e família no cotidiano colonial - Sudeste, século XVIII. Tese Doutoramento - ICFH/UFF, 1994. 
Fernando Franco Netto

\section{Considerações Finais}

Neste artigo procuramos avaliar algumas questões relacionadas com a estrutura de posse de cativos e as trajetórias de alguns proprietários de escravos durante o século XIX. A região está localizada no terceiro planalto paranaense, pertencendo, durante a primeira metade do século, à Comarca de São Paulo, assim como todo o Paraná.

As fontes utilizadas basearam-se nas listas nominativas de habitantes para os anos de 1828, 1835 e 1840 e nos processos de inventários post-mortem para alguns proprietários.

Com a política de ocupação intensificada a partir da primeira metade do século XIX, observamos a evolução da posse média de escravos para os períodos analisados, com um crescimento bastante significativo das mulheres escravas nos plantéis. 0 perfil da estrutura de posse de escravos em ambas as fontes mostra-nos uma razão de masculinidade importante para os períodos selecionados, independentemente do tamanho dos plantéis, ao mesmo tempo em que a preferência por homens escravos se relaciona, muito provavelmente, com suas atividades econômicas voltadas para a pecuária.

O tamanho dos plantéis demonstra um padrão de posse de pequenos plantéis, característica das economias voltadas para o abastecimento interno e com atividades relacionadas com o campo. Apesar disso, encontramos alguns proprietários concentrando a força de trabalho escrava na região, com tamanho de plantel superior a 5 escravos, demonstrando, assim, que a propriedade em Guarapuava também teve uma distribuição não homogênea, face às relações de poder econômico, político e social na localidade.

Quanto ao perfil das propriedades, observamos que a maioria delas era encabeçada por homens, enquanto isso, a idade média dos proprietários evoluiu no tempo, determinando, dessa forma, padrões de posse e de riqueza compatíveis com o ciclo de vida do proprietário. A maioria era casada, mas com importante percentual de solteiros, provavelmente em função da política de migrações que estava acontecendo no período.

Além disso, devemos salientar que a qualidade dos recenseamentos prejudica uma análise mais detalhada de alguns dados, visto o número de proprietários que não possuíam registro do seu estado civil nas listas. Com relação à cor, os proprietários, em sua grande maioria, eram brancos, mas vale aqui a questão anteriormente levantada, quanto às dificuldades encontradas pelo recenseador face às poucas informações sobre esse item.

A posse média de escravos se mostrou crescente nos períodos analisados e, na amostra daqueles proprietários selecionados que se encontram nas 
três listas, observou-se que eles apresentaram posse média superior àquela encontrada para o total dos proprietários. Isso reflete na importância do ciclo de vida e na formação do patrimônio de cada um deles. A relação entre a posse de escravos e a faixa etária dos proprietários confirma a hipótese de que o patrimônio cresce de acordo com a idade, com tendência de queda quando no final da vida dos proprietários. Pelas características do plantel, e de ocupação da localidade, os proprietários apresentam plantéis maiores, no início do período, nas faixas etárias de 20-39 anos, após alguns anos, essa relação se altera, apresentando plantéis maiores naquelas faixas etárias consideradas como medianas.

Ao analisarmos os inventários para alguns proprietários de escravos, observamos a importância da trajetória por eles traçada, visto o valor de suas posses. A evolução no tempo da escravaria é significativa para os padrões estabelecidos para Guarapuava. Os valores dos bens arrolados demonstram um perfil de riqueza importante, principalmente ao verificarmos que a maioria desses proprietários possuía grandes extensões de terras e um número significativo de animais.

Importante ressaltar, no período analisado, as características quanto à posse de escravos e ao valor das terras arroladas que sofrem muitas modificações em função do fim do tráfico internacional de escravos - pelas leis que determinavam limites na aquisição de escravos -, mas também com relação à política de terras, em face de lei de terras de 1850, no momento do arrolamento dos inventários. Entretanto, além de não fazer parte dos objetivos da pesquisa, essas importantes medidas implantadas a partir da segunda metade do século XIX não produzem efeitos diretos no tamanho das posses analisadas.

Artigo recebido para publicação em: 05/06/2013

Artigo aprovado para publicação em: 21/11/2013 